\title{
THE USE OF VIRTUAL REALITY GAMES AS A TOOL TO OVERCOME ACROPHOBIA
}

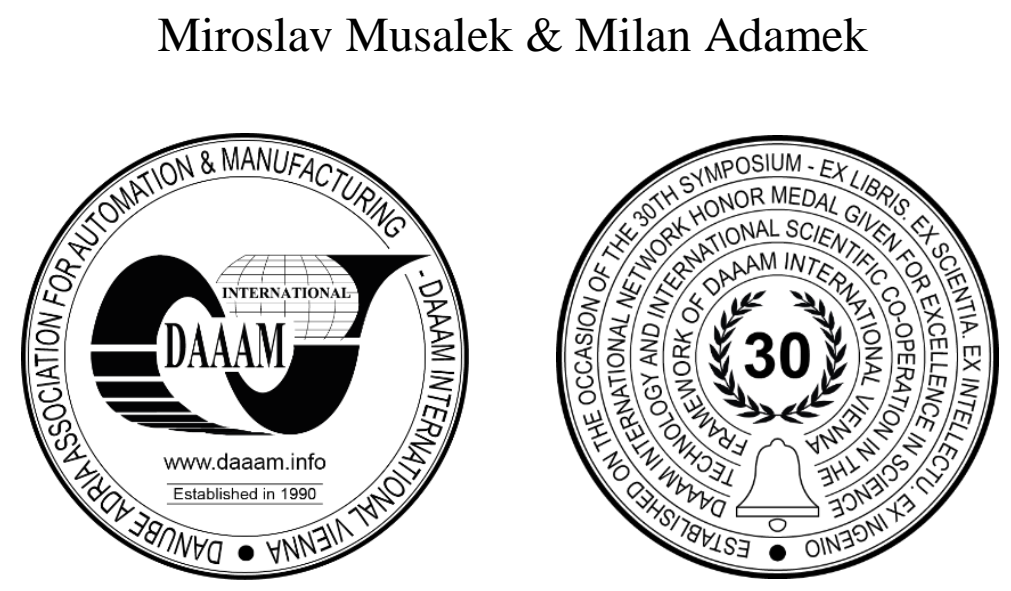

This Publication has to be referred as: Musalek, M[iroslav] \& Adamek, M[ilan] (2020). The Use of Virtual Reality Games as a Tool to Overcome Acrophobia, Proceedings of the 31st DAAAM International Symposium, pp.0485-0489, B. Katalinic (Ed.), Published by DAAAM International, ISBN 978-3-902734-29-7, ISSN 1726-9679, Vienna, Austria DOI: $10.2507 / 31$ st.daaam.proceedings.068

\begin{abstract}
The subject of this article is to ascertain if the use of Virtual Reality can have an impact to fight down the fear of heights. The aim of the suggested and realized pre-research was to use virtual reality as a tool of a fully immersive environment for therapy of fear of heights via VR game. The individuals during VR sessions were monitored for the case that the phobia would have impacted them negatively way. After each session, there was a cooldown part to ease the participants from the stress. The pivotal evaluation of the VR sessions was performed in the form of a psychological test called The Penn State Worry Questionnaire (PSWQ). At the end of the article are the main thought and future directions in this field.
\end{abstract}

Keywords: Virtual Reality; fear; therapy; acrophobia

\section{Introduction}

In recent years, new technological possibilities are developed and applied. This article focuses on virtual reality (VR) and its influence on overcoming the phobia of heights. The pre-research aimed to simulate an environment from which people have phobias. For this purpose, a fully immersive virtual reality was used. We can simulate the environment in which we are currently located, so we simulate the real world that we have physical insight and the simulation can seem more believable. We can also simulate a real environment with some changed property, such as changing its location (Google street view). The advantage of this approach is complete control of the environment and a minimum of danger for patients.

\subsection{Acrophobia}

We refer to the fear of heights as acrophobia, and more precisely it is not only the fear of heights but also of the depths. Of course, most people are not comfortable with heights and depths, but in acrophobia, fear is exaggerated and unfounded.

The patient has an abnormal fear of height, the exact manifestations depend on the severity of the disease. Serious forms mean fear, for example, of a height of several meters, and this significantly disrupts the affected person's ordinary life. An otherwise banal walk up the stairs or a view from a low balcony can also be a problem. 
If the patient enters an environment where fear manifests itself, he usually has problems in the form of fear, nervousness, excessive sweating, and palpitations. An uncontrollable panic reaction can be triggered, and the victim tries to escape, or the fears harden, and he cannot move. Either way, an unexpected panic attack can endanger both the patient and his surroundings [1].

In studies of acrophobia, patients are gradual, with an increasing tendency, exposed to narrow, deep, or raised spaces. The first findings were obtained around 1994, thanks to the Kaiser-Permanente Clinic, which developed a system in which the patient had to withstand conditions at a great height or in narrow spaces, which are very difficult for a person suffering from acrophobia. However, such harsh conditions may not be beneficial for treatment, as they may rather frighten the patient, who may become passive towards their phobia, and thus prefer to stop fighting it [2].

The article [3] describes a situation where 26 persons with a fear of great heights were exposed to VRT gradually increasing heights. Participants were exposed to the following visualizations: a fire escapes with 6 floors in an open space, a roof garden on the building, and a virtual construction site with eight floors. During the simulation, participants could change their height position by one meter. Changes in fear experience were measured using the "A cognition questionnaire", "Presence Questionnaire" and "Subjective units of discomfort" scales, which were evaluated every 5 minutes. Through this research, he achieved a reduction in the avoidance of altitude situations and an improvement in the participants' attitude to heights. However, during the next 6-month follow-up, these acquired properties were not fully preserved.

In the study [4] demonstrates well the value of using VRET in the treatment of acrophobia. The study was designed to best compare the efficacy of in vivo and VRET treatment of acrophobia. The duration of both treatments was 1 hour per week and lasted a total of 4 weeks. During in vivo exposure, patients were introduced to their feared areas, then guided and encouraged by a therapist, who repeatedly encouraged them to look down. The therapist also asked about their level of fear. A total of 33 patients participated in this study, of whom 16 used VRET therapy, and 17 were treated in vivo. All patients were evaluated immediately before and after treatment and also 6 months apart. Both methods were equally effective in the treatment of phobia, also the results of the treatment were very similar even after 6 months, with lasting effectiveness.

Authors in the paper [5] tested the effectiveness of acrophobia self-treatment using a virtual reality application for mobile phones. The research tested 193 people aged 18 to 65 years who suffered from acrophobia. The participants only needed a mobile phone with the Android operating system and low-cost cardboard for their treatment. The application included 6 animated modules. Individual modules were sent to participants within 3 weeks and were implemented in their natural environment. The result was analyzed after the end of the study and after 3 months. The result of the study is that cheap self-treatment based on the application of virtual reality can cause a large reduction in the symptoms of acrophobia. In the paper [6] the influence of VR in seniors on communication disorders and their mental health was monitored.

\section{Material and methods}

\subsection{Virtual Reality}

Virtual reality is a computer-generated simulation of the real world. Many definitions have been developed for the general acceptance of the term "virtual reality". From the often-reducing media used, which VR displays primarily as a display mounted on the user's head, without emphasizing the feedback system, to complex and complex definitions [7]. To create a basic idea about VR, we will use the definition of the psychological dictionary APA, which the VR defines subsequently [8]:

"VR is a three-dimensional, computer-generated environment that a person can explore and interact with - and actually become a part of - allowing them to experience that generated environment as if they were actually there. By applying $V R$ to urban design and planning, planners and landscape architects can immerse ourselves, our clients, and external stakeholders in proposed designs at any stage in the planning or design process, which has a multitude of benefits."

Using its hardware and software, the computer creates a virtual environment in real-time. Entities (objects, characters, etc.) work in real-time and, if appropriate, according to the laws of physics and behavior. The computer monitors the responses of the person interacting with it through its interface. This communication works in both directions via the sensorimotor VR interface. The user performs actions in a virtual environment using motorized interfaces that capture his actions (movements, gestures, etc.). These actions are transferred to the computing unit, which interprets them as a request to change the environment. By this change requirement, the computing unit assesses the changes to be made in the virtual environment and displays the responses (images, sounds, vibrations, etc.)

Components of the HTC Vive: The HTC Vive virtual reality system consists of several parts (Fig. 1.), which together create an overall virtual environment.

Number one shows the main component of the VR system. This is a headset where the generated environment is projected. There is a $3.5 \mathrm{~mm}$ jack connector for audio output. Another element of the VR system, marked by number two, are two VR controllers. Their main function is to control the environment and manipulate the created elements of this virtual world. The VR set also contains two base stations that capture the user's movement. The last part of the whole VR system is the Link-box, where the connection between the VR headset and the computer takes place. 


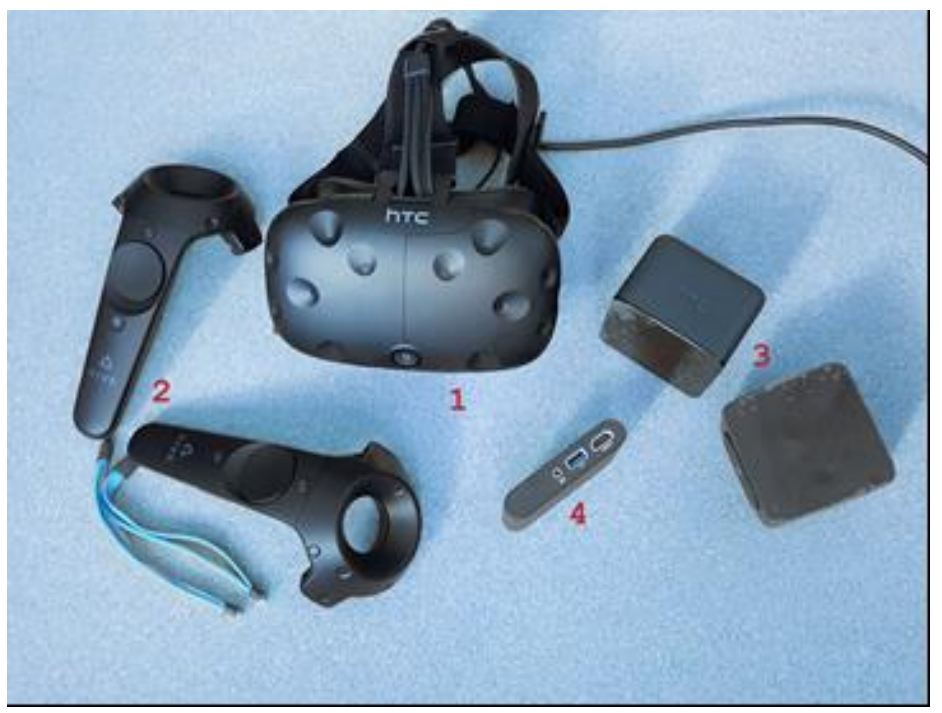

Fig. 1. Components of HTC Vive (1-Headset, 2-Controllers, 3-Base Stations, 4-Link Box)

\subsection{VR game for overcoming acrophobia}

For research purposes was chosen a VR game called Richie's Plank Experience (Fig. 2.). In the virtual world, the participant stands on a wooden board high above the ground. The task for participants will be to get to the end, which is not easy at all. Virtual reality creates the perfect illusion of a high-rise building.

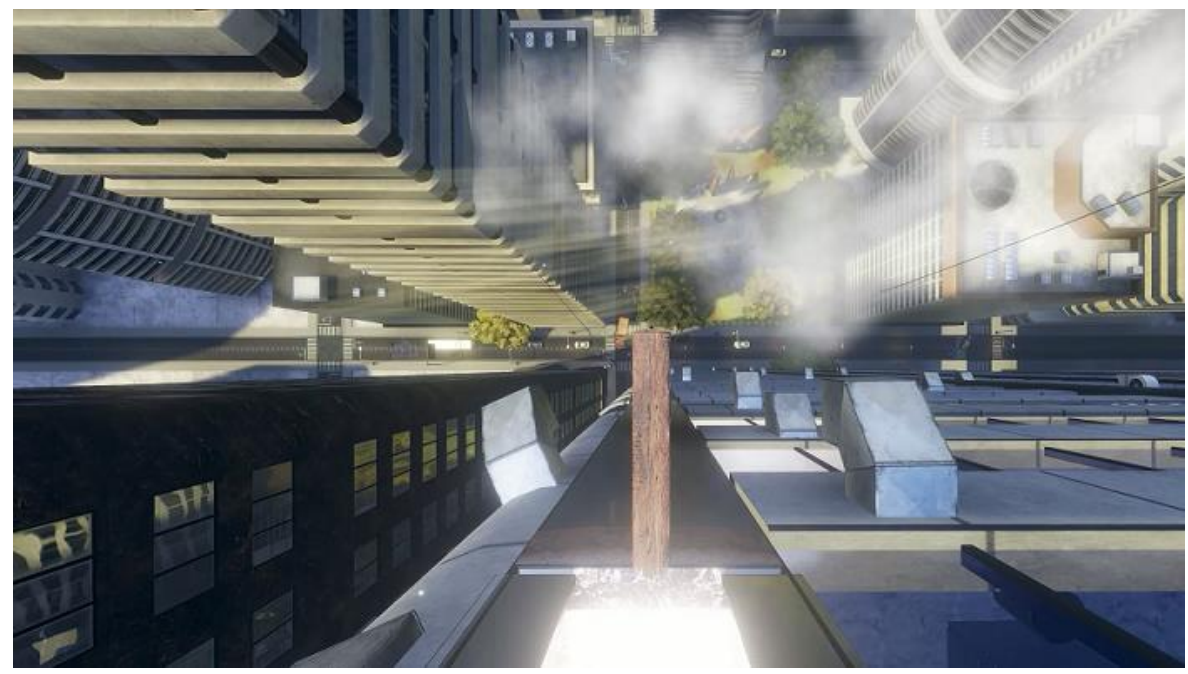

Fig. 2. Richie's Plank Experience game in VR enviroment

\subsection{Procedures and methods of measurement}

The pre-research process involved 20 virtual reality sessions. The goal was to expose participants to phobia from heights in the virtual world through the HTC Vive system. The participant stayed in the VR environment as long as the time until the causes of fear showed up. The experiment worked with two participants, who have a strong fear of heights and often have indisposition and faintness from the view down from the upper floors of the block of flats.

\section{The Penn State Worry Questionnaire (PSWQ)}

PSWQ is a 16-item self-report instrument measuring the trait of worry (e.g., "My worries overwhelm me"; "Many situations make me worry") intended for both clinical and non-clinical populations with good ability to discriminate between them. All items are rated on a 5-point scale (e.g., from "Not at all typical" to "Very typical") stating how typical or characteristic of an individual they are. PSWQ has been shown to have high internal consistency reliability (ranging from $\alpha=0.88$ to 0.95$)$ and good test-retest reliability $(r=.74$ to .92$)$. The possible range of scores is $16-80$ with the algorithm of Total scores: 16-39Low Worry, 40-59 Moderate Worry, and 60-80 High Worry [9], [10]. 


\section{Material and methods}

We have questioned whether virtual reality can be useful in overcoming fear of heights. The pre-research aimed to determine the possible reactions of the tested persons to the virtual environment. The testing did not only influenced the participant's visual perception. For the maximum feeling of perception, the participants were standing on a piece of board, similar to one in a virtual environment.

During the pre-research signs of fear were observed. The patient has an abnormal fear of height, the exact manifestations depend on the severity of the disease. Serious forms mean fear, for example, of a height of several meters, and this significantly disrupts the affected person's ordinary life. An otherwise banal walk up the stairs or a view from a low balcony can also be a problem. If the patient enters an environment where fear manifests itself, he usually has problems in the form of fear, nervousness, excessive sweating, and palpitations. An uncontrollable panic reaction can be triggered and the victim tries to escape, or the fears harden and he cannot move. Either way, an unexpected panic attack can endanger both the patient and his surroundings. Basic information about the participants who were involved in the pre-research can be seen in Table 1.

\begin{tabular}{|l|l|l|}
\hline & Participant 1 & Participant 2 \\
\hline Gender & male & male \\
\hline Age & 33 & 38 \\
\hline Medication & no & no \\
\hline Level of education & secondary & secondary \\
\hline The age when they had their first experience with acrophobia & 8 & 12 \\
\hline
\end{tabular}

Table 1. Overview of general data of the participants involved in the pre-research

The experiment was performed according to the following procedure: each participant was first introduced to the virtual reality environment. In the next step, it was tested whether the participant was sick of the VR headset. Each session started with a test phase and then a rest phase. The last phase of the test, the resting phase, was intended to calm the participant. For this purpose, the VR games like Beat Saber, Google Earth VR, etc. were played here. This phase lasted 15-20 minutes. At the end of the first, fifth, tenth, fifteenth, and last twentieth session, the participants were evaluated by using a special PSWQ questionnaire. The results of these measurements are shown in Table 2.

\begin{tabular}{|l|l|l|l|l|l|l|}
\hline \multicolumn{2}{|l|}{ Number of session } & 1 & 5 & 10 & 15 & 20 \\
\hline \multirow{2}{*}{ PSWQ questionnaire } & Participant 1 & 61 & 58 & 52 & 48 & 44 \\
\cline { 2 - 8 } & Participant 2 & 59 & 56 & 51 & 49 & 47 \\
\hline
\end{tabular}

Table 2. Results of measurement

The results of the measurements show that the therapy on the phobia from the heights has a positive effect by using virtual reality. For the better orientation of the results, their graphic form is used in the form of a graph depicted in Fig. 3.

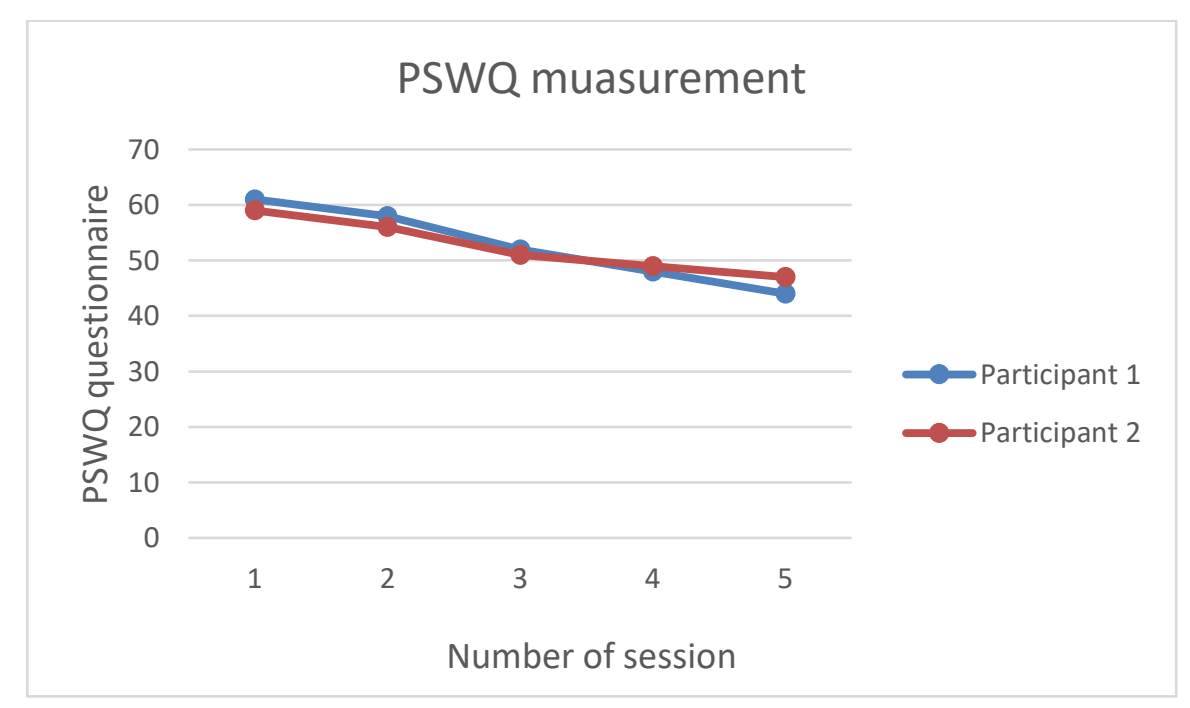

Fig. 3. Comparison of results after sessions in VR by PSWQ questionnaire 
Measured data obtained at the end of the session with the help of a special questionnaire represents possibilities and positive improvements. We can see that the improvement is not entirely linear. It is to a certain extent caused by the individual's individual possibilities when everyone reacts differently.

\section{Conclusion}

The primary goal of the pre-research was to determine whether virtual reality can be used as part of therapy for people with acrophobia. This fear of heights can have a negative impact on the lives of these people.The measurement of this preliminary research was performed on two people with a similar degree of fear. A total of 20 sessions were performed. After the relaxation phase, the PSWQ measuring the trait of worry was performed. In addition, the available feedback with participants provided an opportunity to realize their mistakes or weaknesses and see them from a different perspective. The results of this pre-research show that virtual reality therapies are beneficial.

This approach to using virtual reality has some limiting factors. The limiting factor in this preliminary research is a small group of people. Although the virtual reality has been shown to be positively evaluated in the treatment of acrophobia, further tests will be needed. Another factor is the possibility that over time, the participant will consciously or unconsciously get used to the environment. He can also realize the safety of the real environment.

Further testing of the virtual reality for a person's approach should include multiple variables. Variants with the more unstable ground can be included here. Then adding another scenario into the created environment as a means of changing perception. For people suffering from phobias who have already adapted to a certain height, it will be necessary to increase it or change its environment. Current trends use mainly a limited number of sensory perceptions. A new trend for future research will be the use of haptic gloves in conjunction with a maximally realistic environment with the same projection in a virtual environment. This means that the participant will not only stand but may need to be hung in the air like a climber. It will also be necessary to involve more participants in further research.

\section{Acknowledgments}

This paper was prepared with the support by grant no. IGA/CebiaTech/2020/005 from Internal Grant Agency of Tomas Bata University in Zlin.

\section{References}

[1] Fear of hights. Medicine, diseases, study [online]. Prague [cit. 2020-09-08]. Available from: https://www.stefajir.cz/?q=strach-z-vysek

[2] CRAIG, Alan B., William R. SHERMAN a Jeffrey D. WILL (2009). Developing Virtual Reality Applications .Amsterdam: Elsevier. ISBN 9780123749437. doi:10.1016/C2009-0-20103-6

[3] Emmelkamp, P. M., Krijn, M., Hulsbosch, A., de Vries, S., Schuemie, M., \& Van der Mast, C. A. P. (2002). Virtual reality treatment versus exposure in vivo: a comparative evaluation in acrophobia. Behaviour Research and Therapy, 40(5), 509-516.

[4] Krijn, M., Emmelkamp, P. M. G., Ólafsson, R. P., Schuemie, M. J., \& Van Der Mast, C. A. P. G. (2007). Do Self Statements Enhance the Effectiveness of Virtual Reality Exposure Therapy? A Comparative Evaluation in Acrophobia. CyberPsychology \& Behavior, 10(3), 362-370.

[5] Donker, T., Cornelisz, I., van Klaveren, C., van Straten, A., Carlbring, P., Cuijpers, P., \& Van Gelder, J.-L. (2019). Effectiveness of Self-guided App-Based Virtual Reality Cognitive Behavior Therapy for Acrophobia. JAMA Psychiatry, 1-9.

[6] Kovar, I. \& Musalek, M. (2018). Use of Virtual Reality for the Therapy of Pensioners with Communication Disorders, Proceedings of the 29th DAAAM International Symposium, pp.0811-0816, B. Katalinic (Ed.), Published by DAAAM International, ISBN 978-3-902734-20-4, ISSN 1726-9679, Vienna, Austria DOI: 10.2507/29th.daaam.proceedings. 117

[7] PA. (2020). APA Dictionary of Psychology: Virtual reality. Available from: https://www.planning.org/planning/2019/oct/virtualhorizons/

[8] Fuchs, P., Guillaume, M., \& Pascal, G. (2011). Virtual Reality: Concepts and Technologies. London: CRC Press/Balkema, Taylor \& Francis Group.

[9] Meyer, T. J., Miller, M. L., Metzger, R. L., \& Borkovec, T. D. (1990). Development and validation of the Penn State Worry Questionnaire. Behavioral Research Theories, 28(6), 487-495.

[10] Startup, H. M., \& Erickson, T. M. (2006). The Penn State Worry Questionnaire (PSWQ). In G. C. L. Davey \& A. Wells (Eds.), Worry and its psychological disorders: Theory, assessment and treatment (pp. 101-119). Chichester: Wiley. 